\title{
Knowledge, attitudes and practices to children with disabilities in Bhutan: a contextualized literature review
}

Philip Garner, Jane Murray, David Preece, Richard Rose \& YuZhao

Faculty of Education and Humanities, University of Northampton, Northampton, UK

\section{ABSTRACT}

The challenges of providing education for a heterogeneous student population (in respect of gender, poverty levels, language and learning aptitude and level) have been major issues in refining Bhutanese policy and practice. These challenges are noted in respect of children with 'special needs' in the Bhutan Education Blueprint, 2014-24 (NSB/MoE/UNICEF, 2014), which indicated that 'government's initiatives to enhance educational access for children with special needs remains a formidable challenge for the education sector owing to the limited number of special schools, facilities, support services and capacity of the teachers' (p. 26). This literature review scopes some of the key issues implied by this current situation, using the existing literature on 'children with disabilities' CWD from both recognized academic sources as well as the so-called 'grey' literature. It points to an emerging recognition of both ongoing challenges and opportunities in Bhutan which parallel those in diverse international contexts.

\section{Introduction}

The cornerstone of effective social, educational and vocational provision for children with disabilities (CWD) is the presence of knowledge and its articulation in child-centred practice, informed by positive attitudes of individuals and communities. Given the implications of these interconnected elements for children', it is understandable that these topics have been prevalent in recent literature relating to policy and practice for CWD. Moreover, the knowledge bases, attitudes and practices (KAPs) of people without disabilities compared to those with disabilities are neither homogeneous nor static.

Several established themes populate the historical literature relating to KAPs concerning CWD. Though these have been superseded by more progressive thinking, they provide an insight into the slow emergence of more positive attitudes and associated practices during the last 40 or so years. It should be recalled that Plato recommended that 'deformed offspring' should be segregated in 'mysterious unknown places' (Goldberg \& Lippman, 1974). In the late Middle Ages, Luther and Calvin indicated that the 'mentally retarded' and other persons with disabilities were possessed by evil spirits. The Darwinists of the latter part of the nineteenth century opposed state aid to the 'handicapped', arguing that their preservation would impede the process of natural selection (Hobbs, 1973).

This literature review does not address the in-depth characteristics of the historical aspects of attitude formulation, or the impact of increases in knowledge on policy and practices in respect of CWD. This has been undertaken elsewhere (see, for example, NDA, 2006). Instead, this review seeks to provide an accessible account of the knowledge-awareness, attitudinal characteristics and the practices of key stakeholders towards CWD in Bhutan. In so doing it offers an overview of knowledge (including typology, causes, conventions and laws and available services relating to CWD), attitudes (of a range of key stakeholders) and recent and current practices (as seen from a range of 
perspectives), including those factors which inhibit effective provision. In order to locate this country-specific review in its global context it maps some of the more generic, international dimensions in KAP relating to CWD, before considering the case of Bhutan in detail.

KAP in relation to people with disabilities (PWD) have varied considerably from one culture/community to another. They are subject to changes over time. Kaliyaperumal (2004) provides a summary definition of each KAP element as follows: Knowledge is the capacity to acquire, retain and use information; a mixture of comprehension, experience, discernment and skill; Attitudes refer to inclinations to react in a certain way to certain situations; to see and interpret events according to certain predispositions; or to organise opinions into coherent and interrelated structures; and Practices mean the application of rules and knowledge that leads to action. (p. 7) This literature review adopts these definitions and maps the continuities and differences between their recent and contemporary characteristics in Bhutan and internationally.

\section{Bhutan: the country context}

Bhutan is a country in the Himalaya region, described as a 'small state' (Schuelka, 2013). It has experienced rapid societal changes, particularly in the post-World War II era. Some dramatic changes have been experienced in Bhutan's educational system. From only partial provision 50 years ago, the education service now caters for the entire population of Bhutan up to age 18 . The challenges of providing education for a heterogeneous student population (in respect of gender, poverty levels, language and learning aptitude and level) have been major issues in refining Bhutanese policy and practice. The Bhutan Ministry of Education (2012b, p. 36) states that all CWD and with special needs - including those with physical, mental and other types of impairment - will be able to access and benefit from education. This will include full access to the curriculum, participation in extracurricular activities and access to cultural, artistic, recreational and leisure activities. Bhutan'sNational Policy on Special Educational Needs (National Statistics Bureau/Ministry of Education/UNICEF, 2014) emphasized that every child with special educational needs (SEN) has equal access to quality education that is more appropriate, enabling and responsive and that children with special educational needs should become independent, responsible and productive citizens. To achieve this, the National Policy recognizes that it will be necessary to 'Enhance awareness and sensitization on special educational needs... and create awareness and advocacy on the rights and responsibilities of children with special educational needs' (p. 9).

In Bhutan over $21 \%$ of children aged 2-9 years have one or more disabilities. This figure is endorsed by Dorji (2012) who has additionally indicated that $31 \%$ of households with CWD experience conditions of absolute poverty; the latter is commonly aligned with SEND populations, irrespective of country location (Singal \& Muthukrishna, 2014). One of the challenges for Bhutan is to ensure that all children with SEN and CWD receive appropriate education and social services (Cokl, 2010). Consequently, recent policy has emphasized enabling full access and participation of CWD to such services, leading to a greater sense of awareness about the rights of CWD in Bhutan, as evidenced by the increasing enrolment of children in Drukgyel School for the Hearing Impaired from seven in 2004 to 77 in 2013. CWD have increasingly been brought by their parents to Changangkha Middle Secondary School, which offers inclusive education (UNICEF, 2013a).

It is nevertheless stated that more work is needed for a paradigm shift from the medical model of disability to a social model (Samaha, 2007; Shakespeare \& Kleine, 2015; UNICEF, 2007). In Bhutan, a regional seminar on inclusive education (UNICEF, 2013b) enhanced awareness amongst key stakeholders to work towards a more inclusive approach. UNICEF's 2013 study indicated a 'dearth of information on the on the nature, prevalence and more importantly the profile of children living 
with disabilities in Bhutan'. Such a shortfall inhibits policy development and planning to provide appropriate services to meet the needs of CWD.

\section{Review methodology}

This review adopts a purposive selection of material to provide a synthesis of wide-ranging material relating to attitudes towards CWD within households and the wider community, defined for the purposes of this review as '... a group of people with diverse characteristics who are linked by social ties, share common perspectives, and engage in joint action in geographical locations or settings' (Mac-Queen et al., 2001). The review utilizes resources from several academic disciplines, including psychology, sociology, education and health studies. Its sources comprise government reports, NGO papers, monographs, journal articles and unpublished Doctoral theses, as well as the 'grey literature' (unpublished material) including online resources and media reports.

The review is almost exclusively restricted to post-2000 materials. Exceptions are made when utilizing sources that illustrate the historical dimensions of KAP and CWD and established international conventions to which Bhutan is a signatory. Texts were sourced through a thematic search approach using standard academic search engines (see Figure 1).

This approach was assisted by a 'reference group', comprising 5 academic colleagues from UK, USA, Australia and mainland Europe, identified according to criteria linked to the project's orientation and needs. Each had (a) over 15 years professional experience in the field of disability/special educational needs (b) a record of research-based published work in the field (c) a doctoral qualification in a field appropriate to the review (d) experience of international research and consultancy.

The review adopts the following definitions:

Household: this includes all of those who share a dwelling, whether related by kinship or otherwise.

Disability: the current World Health Organisation (WHO) definition is used, which covers impairments, activity limitations, and participation restrictions. An impairment is a problem in body function or structure; an activity limitation is a difficulty encountered by an individual in executing a task or action; while a participation restriction is a problem experienced by an individual in involvement in life situations.

Children: The United Nations Convention on the Rights of the Child defines a child as 'a human being below the age of 18 years unless under the law applicable to the child, majority is attained earlier' (UN, 1989).

\section{The international context of knowledge, attitudes and practices regarding CWD}

Knowledge about CWD in education and social care fields has changed significantly over the last 40 years, leading to shifts in attitudes and practice. Birch and Johnstone (1975) believed that schools and communities should demonstrate the same readiness and accessibility to PWD as to those without disabilities. This period has been characterized by an international drive to define and articulate a philosophy of inclusion. Several statements of intent and international conventions have helped to reinforce the view that, in contemporary nation states, CWD should have full access to resources and opportunities (UNESCO, 1994; United Nations, 1989). 


\section{Knowledge regarding CWD internationally}

Individual countries have sought to formulate policies and practices to enable CWD to participate more fully in educational, social and economic processes. Initially a common trend has been to adapt pre-existing institutional frameworks to integrate CWD. One example was the so-called mainstreaming approach, which enabled CWD to enrol in regular schools. However, these early efforts sometimes compounded the difficulties experienced by CWD because there was little concentrated effort to shift attitudes towards them. This still left them feeling discriminated against and vulnerable within their communities. Such a pattern of experience has been evident globally; for instance, a study of children with SEN in the UK (DCSF, 2007) reported that $55 \%$ said they had been treated unfairly because of their disability. These and other studies indicate that inclusion of CWD is not a straightforward or uncontested process.

Nevertheless, international recognition of the Education for All movement has been a feature of post-2000 development, with attention directed specifically towards 'equalisation of opportunity' confirmed by UNESCO (2000) and the United Nations (UN) (2006). New UN initiatives have the overarching intention of incorporating CWD into all current and future Sustainable Development Goals (SDGs) efforts (United Nations, 2009), indicating recognition of an explicit link between disability and poverty. A focus on poverty reduction is thus a goal of the recent WHO guidelines oncommunity-based rehabilitation (WHO, 2012) and it is also highlighted in the WHO/World Bank World Report on Disability (WHO/World Bank, 2011).

Acceptance that 'inclusive practices' relates to more than PWD and learning difficulties (Winter \& O'Raw, 2010) has been a feature of post-2000 developments. It is now understood more in respect of barriers to learning and participation experienced because of gender, personal history, race, ethnicity, language, care status, socioeconomic status, sexuality, or religion (Gerschel, 2003). This is an important consideration, given that levels of knowledge about disabilities can vary as a result of the impact of one or more of these factors. There has been a firm recognition of the linkages between disability, poverty and health. Whilst poverty is seen as both a cause and consequence of disability (Zimmer, 2008), there is widespread acceptance that multi-factorial explanations are essential starting points for interventions. These are apparent in both high-GDP and low-GDP settings (Croot, Grant, Cooper, \& Mathers, 2008).

Increased knowledge regarding causation has resulted in greater public awareness (SCOPE, 2014; WHO, 2011), with 'Most countries that have developed support services have strong organizations of persons with disabilities and their families lobbying governments to reform policies on service delivery and to increase or at least maintain the resources allocated' (WHO, 2012, p. 147).

The policy implication of becoming a signatory to international conventions on disability and children's rights has been widely recognized (Thomas, 2011), and resulting legislation in nation states across diverse regions has been apparent (OECD, 2005). In most cases, national legislation has incorporated recommendations regarding approaches to intervention. Evidence also suggests that 'inclusive education is most effectively promoted by a comprehensive strategy to teacher training and community-based approaches which promote inclusive cultures, values, beliefs and attitudes' (Reiser, 2013).

\section{Attitudes regarding CWD internationally}

A body of research-led opinion suggests that the attitudes of others to CWD represents the key factor in their social, educational and cultural inclusion (Ainscow, 2005). Beliefs and expectations vary within and between these broad groupings. Literature relating to attitudes indicates a level of 
consistency, notwithstanding the country setting or relative stage of development (Al Zyoudi, Al Sartwai, \& Dodin, 2011; de Boer, Pijl, \& Minnaert, 2011; EADSNE, 2011). Parents' views regarding disability, whether these relate to their own or others' children, are prominent in the literature. Parents of CWD are viewed as wanting their children to be included in educational and social settings (Leyser \& Kirk, 2004), although there are indications that some are concerned about the absence of the necessary skills or awareness amongst mainstream communities (Rafferty \& Griffin, 2005). Parents of children without disabilities were more likely to view the inclusion of CWD in mainstream settings as problematic (de Boer \& Munde, 2015). parents' attitudes vary according to a range of factors, including availability of support services, religious or cultural orientations and peer pressures (Hassanein, 2015).

The attitudes of professionals who come into close contact with CWD reveals a similarly complex picture. For example, Finke, McNaughton, and Drager (2009) indicate divergent opinions regarding children with autism. The existence of such diverse, even polarized, attitudes of teachers is a major barrier in securing effective provision for CWD (Purdue, Gordon-Burns, Gunn, Madden, \& Surtees, 2009) whilst commentators suggest that such attitudes might be subject to change following periods of professional development (Carroll, Forlin, \& Jobling, 2003). A similar situation has been noted with regard to other professional groups who interact regularly with CWD (Baker-Ericzén, Mueggenborg, \& Shea, 2009).

Hassanein (2015) indicates that a range of factors have been implicated over time that influence the emergence of an attitudinal response to CWD from any given group. These may prompt either positive or negative response reactions. For example, the international literature indicates evidence of a range of personal feelings to disability: the guilt experienced by parents is particularly noted (Lemacks, Fowles, Mateus, \& Thomas, 2013). Such feelings can be reinforced by negative imagery and language, stereotypes, and stigma which persist for CWD around the world (World Bank, 2009). Moreover, there is evidence suggesting that the general public lacks an understanding of the abilities of people with intellectual impairments (Siperstein, Norins, Corbin, \& Shriver, 2003), contributing to the adverse labelling of those with disability (Gibson, 2008). In contrast, the existence of a network of supports and resources can result in a more positive stance, both by teachers and by parents of CWD (Elkins, van Kraayenoord, \& Jobling, 2003).

\section{Practices regarding CWD internationally}

Since the Salmanca Statement (UNESCO, 1994) there has been a steady refinement of societal and educational approaches to meeting the needs of CWD, with the global adoption of the principles of inclusive practice. This has been the dominating theme informing developments for CWD (ARACY, 2015; Booth \& Ainscow, 2002; EADSNE, 2012; Osberg \& Biesta, 2010; UNESCO, 2005). Conversely, CWD, particularly those experiencing mental health issues, have been over-represented in exclusionary practices in most countries (Parker \& Ford, 2013; UNICEF, 2007) and are regarded by practitioners as children least likely to benefit from participating in inclusive environments (Cassady, 2011).

Effective practice in supporting CWD, whether in formal settings such as schools or kindergartens or informally within social groups within neighbourhoods, has been a salient, feature in the literature. School curriculum practices (Meijer, 2001), pre-school support (Skotko \& Canal, 2005), access to support services (Parker, Gage, \& Sterr, 2011), leadership practices (Chapman et al., 2011) and the degree to which CWD are enabled to participate within community activities (Clarke, 2006) are further illustrations of the scrutiny given to emerging practices for CWD. 


\section{Knowledge, attitudes and practices regarding CWD in Bhutan}

This section reviews literature addressing aspects concerning knowledge about CWD in Bhutan. In relative terms, 'Little is known about the nature, type and possible causes of CWD in Bhutan' (UNICEF, National Statistics Bureau, Ministry of Education, Ministry of Health, 2012). However, in recent years an increasing variety of literature has become available, providing evidence for a credible scoping of the current status of knowledge, attitudes and practicestowards CWD in this hitherto inaccessible nation state.

\section{Knowledge regarding CWD in Bhutan}

Disability is defined by the Royal Government of Bhutan (RGoB) (2012) as

....an inability or a reduced capacity to perform a task in a specific way....a limitation imposed on an individual by a loss or reduction of functioning, such as the paralysis of leg muscles, the absence of an arm, or the loss of the sight. In other words, disability can be interpreted as the incapability to perform as other children do because of some impairment in sensory, physical, cognitive or other areas of functioning. These limitations make children incapable of doing what other children do. Therefore, a 'disability' is the functional consequence of the impairment. (p. 19)

When a person's daily activity is inhibited by their disability in Bhutan, they may be regarded as deprived (Ura, Alkire, Zangmo, \& Wangdi, 2012). For the Bhutanese population, disabilities are assessed and reported as a health status indicator within Bhutan's Gross National Happiness Indicators (Beaglehole \& Bonita, 2015; RGoB, 2012). Cognitive disabilities are those most frequently identified amongst children in Bhutan (Mont et al., 2013). In international comparisons, Bhutan scores relatively poorly in measures of psychological wellbeing (Biswas-Diener, Diener, \& Lyubchik, 2015), though the diagnosis rates of mental illness are rising as health workers become better trained: anxiety, stress-related illness, epilepsy and depression account for $82 \%$ of mental illness in children and young people in Bhutan (Dorji, 2004).

A higher prevalence of disabilities has been noted amongst poor children and those of mothers with relatively little education, particularly children with moderate and severe disabilities (UNICEF, n.d; Mont et al., 2013). Mont et al. (2013) propose that children's disabilities may vary according to their mothers' education levels and, conversely, that better maternal education prevents mild disabilities from escalating. Moreover, UNICEF (n.d.) found a higher incidence of disabilities in younger children and those living in rural areas. Together with several Bhutanese government partners, UNICEF undertook a study focused on CWD, described as 'a significant advance to better understand the extent, nature and degree of disability in Bhutan among children aged 2-9 years' ( $p$. i). The study found an overall prevalence of $21 \%$ of CWD, ranging from $26 \%$ for the poorest children to $14 \%$ for children from the wealthiest families. Mild disability accounted for $19 \%$ of CWD, moderate disability accounts for $2 \%$ and severe disability accounted for $0.7 \%$ of (UNICEF, 2013b). Amongst CWD, $14 \%$ had a single impairment while $8 \%$ presented with co-morbidity. Prevalence of disability amongst children aged $2-5$ years was $27 \%$, whilst the rate was $16 \%$ amongst children aged $5-9$ years. The study found no significant gender differences in each grouping. Nevertheless, the potential causes of disability appear under-researched in Bhutan (Mont et al., 2013).

Concern for child protection is evident in current policy (Parliament of the Kingdom of Bhutan, 2011; Youth Development Fund Secretariat, 2014) and the need to educate the general population about disabilities, including parents and service providers, is recognized, since the absence of such knowledge often means Bhutanese children do not access services (Lham, 2013; UNICEF, n.d.). Yet official policy does not always appear to advocate as robustly as it might for CWD; for example, 
whilst Bhutan's Child Care and Protection Act (Parliament of the Kingdom of Bhutan, 2011) articulates the need to address 'matters relating to children in conflict with law in the most favourable (sic) manner and in the best interest of the child' (p. 1) most of the document focuses on children who have committed crime.

There are discontinuities between policy and practices regarding models of disability in Bhutan. Whilst a social model is promoted at policy level (Schuelka, 2013), a medical model prevails in practice with little recognition of the value of inclusive education amongst the general population (UNICEF, 2013d). This may partly be due to 'attitudinal barriers' in tandem with specific social norms that seem to contribute to preventing CWD from accessing their rights (UNICEF, n.d.). Nevertheless, both social and medical models of disability are discussed increasingly openly in contemporary Bhutan (Schuelka, 2015). Bhutan is a signatory to the UN Convention on the Rights of the Child (United Nations, 1989) and the country has signed - but not ratified - the UN Convention on the Rights of People with Disabilities (UNRCPD) (UN, 2006) (Schuelka, 2015). The Constitution of Bhutan is committed to supporting citizens with disabilities to access their rights UNICEF (2013c). However, there is no statutory disability act (UNICEF, n.d.) and civic amenities and infrastructure are regarded as inadequate to enable access for PWD (Business Bhutan, 2012).

In Bhutan, the United Nations (UN) has been influential in promoting an approach to disability that is 'rights based'; in other words, it has been encouraging the adoption of a social model of disability (Schuelka, 2015). Moreover, Bhutan's development approach includes a focus on rights of equality in law for all people, including those with disabilities, manifest in education, health, and the workplace (Pellegrini \& Tasciotti, 2014).

While school enrolment and completion rates have risen in recent years, in 2012, Bhutan government statistics indicated that $2 \%$ of children were still not in school, with the lack of provision for children with special learning needs identified as one explanation (RGoB Ministry of Education (MoE), 2011; 2012a). On the other hand, UNICEF et al. (2012) state that there are no specific data on out-of-school CWD. Tharchen and Savegpan (n.d.) estimate that there are more than 3,300 children in Bhutan with 'immediate special learning needs' ( $p .1$ ). Although children with SEN and disabilities who are not in school pose a concern for Bhutanese teachers (Chhetri, 2015), poor institutional and human resources are often the reasons why CWD are denied access to education (UNICEF, n.d.). In addition, Chhetri (2015) found that there is a lack of awareness about inclusive education among parents of CWD.

All government policy, including education policy, is grounded in Buddhism (Givel, 2015) and, until the 1950s, formal education in Bhutan was exclusively the domain of Buddhist monasteries (Childs, Tenzin, Johnson, \& Ramachandran, 2012). Subsequently, educational provision has become more widely available, aligning more closely with international policy (RGoBMoE, 2012a). Contemporary education in Bhutan is free from 6-16 years, though there is some disparity in the literature regarding if it is compulsory (RGoBMoE, 2014; UNICEF, 2013c). Access to education is generally characterized by gender parity (Schuelka, 2013) though school costs for children aged 14-16 years tend to rise and parents tend to favour boys in that context (Choden \& Sarkar, 2013). A concern for 'quality' is highlighted by a national assessment programme (Maxwell, Rinchen, \& Cooksey, 2010), though a legislative framework does not currently exist to secure entitlement for CWD to education (UNICEF, 2013c).

Early Childhood Care and Development (ECCD) provision is emergent but progressive, informed by the MoE's 2014-2018 Five Year Plan for Bhutan and Early Learning and Development Standards (ELDS) (Wangchuk, Choden, Choden, Zangpo, \& Yangden, n.d.). In 2012, a National Policy on Special 
Educational Needs was developed, aiming for 'a caring, inclusive and enabling society' by ensuring that ' ...every child with special educational needs has equal access to quality' and empowering 'all children with special educational needs to become independent, responsible and productive citizens' (RGoBMoE, 2012a, p. 7). Moreover, RGoBMoE (2014) 'seeks to maintain an inclusive approach to improve educational access and meet the special needs of those with physical disabilities and learning difficulties' (p. 18). Nevertheless, Bhutanese educational policy and investment seems more focused on segregation than inclusion (Pinnock, 2013; UNICEF, 2013c).

The National Policy on Special Educational Needs (RGoBMoE, 2012a) identifies the need for an accessible learning environment and additional support services for children with identified SEN, including 'trained teachers, teaching approaches, equipment and care within or outside a regular classroom' (p. 6). Teacher education in Bhutan is in need of significant reform (VanBalkom \& Sherman, 2010; Wangchuk et al., n.d.), while Bhutanese teachers believe their classes are too large and they have insufficient knowledge, training and resources (Chhetri, 2015; Lham, 2013; Zangmo, n.d.); However, most of the teachers in Chhetri's study indicated that although they found it difficult to put their knowledge of inclusive education into practice, they had good theoretical understanding (Chhetri, 2015). They were also concerned about weak public understanding regarding education for CWD, lack of inclusion policies in schools, academic standards and their own professional development. In respect of engaging CWD in education, Pinnock (2013) also identifies that Bhutanese teachers need more access to professional development, particularly learner centred teaching.

Nevertheless, UNICEF (2013c) identifies that the trajectory for improving the quality of inclusive education in Bhutan appears promising. $\operatorname{RGoBMoE}(2014$, p. 18) noted that by 2014 , there were two SEN centres and six integrated schools where 255 teachers support 366 children with SEN. UNICEF (2013c) suggested that these, together with SEN specialist teacher training courses, give teachers access to expertise aboutCWD. Furthermore, in 2014, a conference organized by the RKB Ministry of Health, RENEW, UNICEF and WHO focused on mental health issues for CWD (UNICEF, 2014) and the National Institute of Visually Impaired and a new NGO office address the needs of at least some PWD in Bhutan (Zangmo, n.d.).

\section{Attitudes regarding CWD in Bhutan}

This section reviews literature focused on the attitudes of parents, professionals, community members, policymakers and NGOs in Bhutan. Some general points regarding attitudes towards CWD are addressed first. Bhutan's religious and cultural history affects the attitudes of its people: this is manifest on the one hand by compassion as a national characteristic (Brooks, 2011; Schuelka 2015) noting that such compassion often means that parents of CWD 'pamper' their children to the extent that they do not learn life skills (p. 825). On the other hand, Bhutan's religious and cultural history has resulted in a widespread belief in karma - 'a wrong or base behaviour that is expected to negatively affect the state of one's reincarnated soul' (Metz, 2014, p. 224). UNICEF (n.d.) notes that this view of past karma translates to social norms which result in CWD being regarded as unproductive and not worthy of equal treatment. The adoption of happiness as the aim for development has emerged in this religious and cultural context (Alkire, 2015; Ura et al., 2012). UNICEF et al. (2012) note that CWD and children with SEN are 'often marginalised'; they advocate the need for stakeholders to ensure that these children ' ... have equal access to basic services such as education, health care and social protection' (p. i).

References to parents in Bhutan's annual education report diminished between 2009 and 2015 (RGoBMoE, 2009, 2014), yet government views communication between parents and formal 
education institutions as important (RGoBMoE, 2014). The inclusion of parents of CWD alongside policy-makers and professionals in a regional seminar focused on inclusive education (UNICEF, 2013d) suggests that positive attitudes amongst parents of CWD are valued in Bhutan by professionals whose work concerns CWD.

When Thuji (2013) researched attitudes towards the role of civil society organizations in inclusive education development in Bhutan she noted that all responding parents believed children should be included in education in Bhutan. However, Chhetri (2015) found that many parents in rural villages do not regard education as important for their CWD, principally because they believe that such children cannot undertake tasks for themselves and will not be productive as adults. In contrast, Chhetri (2015) also found that parents of children who do not have disabilities prefer that their children are not taught in the same class as CWD.

Schuelka (2015) found that medical factors as explanations for disability are beginning to usurp karma amongst the general population; particularly among parents of CWD. Moreover, he found that parents of CWD often believe that a medical cure can be found for their child's condition (Schuelka, 2015). Chhetri (2015) identified a conflict in respect of Bhutanese parents of CWD: many believe that the education of their CWD is the school's responsibility but others regularly volunteer at their children's inclusive schools to support their child's learning and personal needs.

In research about attitudes to the role of civil society organizations in inclusive education development in Bhutan, Thuji (2013) found that all responding teachers believed that CWD should be included. However, Chhetri (2015) indicated that teachers in Bhutan 'are greatly concerned about the acceptance of students with Special Educational Needs' (p. ii). Equally, Lham (2013) found that teachers believed that children with communication difficulties were less suited to inclusive classrooms than children with some other disabilities or SEN. A study by Solomon and Dorji (2009) investigated the attitudes of doctors and nurses to PWD and suggested that 'Bhutanese doctors and nurses appear to hold less positive attitudes toward persons with disabilities than their counterparts from western countries' (p. 32).

'Community vitality' is a key domain within Bhutan's GNHI (Ura et al., 2012), indicating that the country as a whole values community: 50-60\% of Bhutanese people enjoy 'sufficiency' in community relationships (Ura et al., 2012). The powerful influence of Buddhism within Bhutanese communities (Brooks, 2011), underpins Pinnock's finding (2013) that social attitudes regarding disability in Bhutan often mean that CWD do not go outside their homes. Schuelka (2015) notes that disability is regarded as a 'bad omen', so that people with moderate to severe disabilities, such as autism or cerebral palsy, are usually not visible in the community. UNICEF (2013c) observes that community members are reticent about getting involved in school life because they believe teachers should have responsibility for learning and teaching. Nevertheless, in health contexts, Dorji (2004) noted that community stakeholders may be well placed to support people with mental disorders. Similarly, UNICEF (2013d) recommended that Bhutan should continue to develop its education provision for CWD by drawing on community support networks. Nevertheless, Schuelka (2015) found some negative attitudes among Bhutanese communities towards CWD. He noted PWD were being abused with derogatory name calling in their communities; for example 'tsagay', meaning either 'my stupid little one' or 'retarded'. Schuelka (2015) also found Bhutanese people ready to mock physical differences in others, which his respondents stated were 'quite emotionally damaging' (p. 826).

Within the context of Bhutan's Gross National Happiness agenda, Schuelka (2015) notes that some organized attempts are gathering momentum to shift community attitudes and perceptions concerning people with disabilities. Emerging from the work of the Commission, the position of 
national policymakers in Bhutan regarding CWD appears oriented to inclusion and self-reliance (RGoBMoE, 2014; UNICEF, 2013d). However, national policy has tended to result in integration and specialist provision, rather than inclusion (UNICEF, 2013c; Chhetri, 2015). Even among national policymakers, there seems to be an assumption that adults with disabilities will not work: in the Bhutan Living Standards report, the term 'economically inactive' includes all who are 'permanently disabled' (National Statistics Bureau, Bhutan and Asian Development Bank, 2012, p. 96). This policy perspective may be one reason for the reluctance of some parents to ensure their CWD attend school (Chhetri, 2015).

In Bhutan, UNICEF has advocated for CWD by promoting a social model of disability and inclusion (UNICEF et al., 2012; UNICEF, 2013d), by funding and co-funding scoping projects, reporting on the country's progress and raising awareness about the rights of CWD. UNICEF (2013d) has proposed a more inclusive approach to education and also advises stakeholders, including policymakers, to give primacy to programmes that may secure equal access for CWD to education, health care and social protection (UNICEF et al., 2012). Speaking on behalf of Ability Bhutan, a prominent NGO working to support CWD, Thuji (2013) indicated that NGOs and civil service organizations were regarded by teachers, parents, civil servants, students and people with disabilities as significantly more visible in their advocacy for the rights of people with disabilities than the government itself.

\section{Practices regarding CWD in Bhutan}

Despite proposals within the government's Education Blueprint (2014-2024) there is an absence of concrete evidence that practices aimed at securing recognition of rights for CWD and their inclusion are emerging in Bhutan. For example, reviewing teacher education in Bhutan, VanBalkom and Sherman (2010) make no reference to inclusion. UNICEF (2013c) confirmed that CWD are excluded, contrary to Article 7 of the UNCRPD (United Nations, 2006) and Young (2009) noted that CWD in Bhutan are excluded from learning that may improve their lives. It seemed a positive step, then, that a 'division of special education services' was established in 2011 in the Department of School Education (RGoBMoE, 2012a). Equally, Pinnock (2013) highlights an 'increasing demand in Bhutan for children to be educated in mainstream settings' and RGoB MoE (2012b) states its commitment to providing high quality SEN services in Bhutan to '... break the cycle of invisibility and deprivation by bringing every child with SEN into the forefront of any developmental activity' (p. 6).

Bhutan established its first school for children with visual impairments in 1973 (RGoB MoE, 2012b) and by 2014 , there were six integrated schools and two special education centres supporting 366 children with special needs in Bhutan (RGoBMoE, 2014). UNICEF (2013c) highlights two schools that are educating CWD. Drugkyel is a mainstream school with a unit for children with hearing impairments where teaching is segregated. Although Changangka Lower Secondary School has a resource centre for children with severe disabilities, it has adopted inclusive practices for children with mild disabilities. It has been noted that its large class sizes and limited classroom space present challenges for such work (UNICEF, 2013c). Gordon (2013) reported that she felt 'powerless and stunned' following a discussion with a school principal in Bhutan who observed:

Bhutan is way behind in being able to identify and assist youth with basic learning problems. Any help in this area would be most welcome. We need strategies to work with the learning disabled; they are left behind. Teachers lack the skills and with forty to fifty students in the class, it is impossible to attend to them. (p. 297)

Early detection and identification of children's disabilities seems irregular in Bhutan (UNICEF, n.d.) where early assessment and intervention for CWD are new practices; Pinnock (2013) noted 
'opportunities to address disability in the early years must be taken'. Mont et al. (2013) also supported the need for early assessment in Bhutan, alongside 'parental education and outreach for early child development' (p. 18).

The Two-Stage Child Disability Study (NSB/MoE/MoH/UNICEF, 2012), conducted in 2010-2011 was the first to attempt to ' ...estimate the prevalence of childhood disabilities among children 2-9years in Bhutan' (p. 33). Conducted in a country context in which 'Little is known about the nature, type and possible causes of childhood disabilities' (p. i), the study's authors regarded it as a 'significant advance to better understand the extent, nature and degree of disability in Bhutan among children aged 2-9 years' (p. i). It investigated factors associated with childhood disabilities and gathered data on the prevalence of mild, moderate and severe disabilities, of disabilities according to functional domains and of children presenting with single disabilities and comorbidity. The study adopted the Rapid Neurodevelopmental Assessment tool, which is now used for training workers across Bhutan's Health and Education sectors in early assessment and intervention for CWD.

Solomon and Dorji (2009) suggested that gaining greater understanding of health workers' attitudes towards PWD might facilitate appropriate interventions. Nevertheless, UNICEF (n.d.) notes that a secure system for post identification referral and follow-up is not yet in place. ECCD provision is also very new to Bhutan - only in 2013 did the Ministry of Health acknowledge its value as an element in an integrated set of services for young children (UNICEF, 2013d). In 2013, only about $5 \%$ of children aged 3-5 years were in pre-primary school provision (UNICEF, 2013e), though more than thirty new ECCD centres were opened in remote areas of Bhutan by 2014 (UNICEF, 2014).

In relation to access and accessibility for CWD, Dorji (2004) identified the need for facilities in urban areas to support 'mentally retarded' children (p. 623). Zangmo (n.d.) meanwhile denoted specific challenges for those living with disabilities in rural areas: the country is mountainous, buildings are not adapted for PWD, footpaths are poor, and drivers drive too fast making it unsafe for PWD. Business Bhutan (2012) reported that special educators Pema Chhogyel and Deki Zam identify Bhutan's infrastructure as the main challenge for its PWD gaining access: ' ... nothing is disabled friendly... ramps should be made available in public services areas like bank, post office, bus station and hospital' . Chhetri (2015) agrees, arguing for improved IT and '... adequate recreational facilities and play equipment in all common areas, such as children's parks and school playgrounds' (p. 99).

Equally, UNICEF (2013c) states that currently 'There is no clear authority which can be appealed to if a child with disabilities is denied access to school' (p. 44) and it advocates three practical approaches to support CWD to gain access to education. The first is the adoption of a 'School Improvement Plan approach' - a way to engage all stakeholders in finding ways to promote participation and engagement of CWD. The second is the use of distance learning techniques, though this is unlikely to maximize social inclusion and the third is assessment support in the form of Braille, large print documents and providing additional time. Gordon (2013) found that parents in Bhutan are desperate for improved provision for their CWD. On visiting a school for the deaf she noted that:

Parents with children who have other special needs that are unrelated to the deafness plead for them to be allowed to be admitted. This has created an extremely difficult and emotionally wrenching situation for the staff as they turn away children for whom they have no expertise to serve. (p. 297).

Curriculum differentiation and individualization are challenging for teachers in Bhutanese schools which '...implement $100 \%$ national based school curriculum' (Tharchen and Savegpan n.d., p. 82). Scheulka (2015) argues that 'Bhutanese schools construct disability through structure, curriculum, 
and pedagogy' (p. 821) whilst Chhetri (2015) notes that values in Bhutan's Gross National Happiness agenda have 'infused' the school curriculum (p. 2). Tharchen and Savegpan (n.d.) explain that every aspect of curriculum is centrally decided so that teachers have little or no autonomy. However, they found that $83 \%$ of teachers believed that the curriculum frequently inhibits children's access to education if they have SEN. Pinnock (2013) identifies a 'lack of clarity' on how to secure appropriate practice in schools for CWD, and teachers want training in adapting the curriculum to their students' needs (Chhetri, 2015). Zangmo (n.d.) teaches girls with disabilities in a rural area and provides an enhanced curriculum:

Besides the Academic session, there are other activities that are taught in the school.

1. ADL. This is one of the important living skill that is taught in the school to make each disabled person independent. We are taught how to cook, housekeeping and to be self-independent at home and outside.

2. Orientation and Mobility training. This is a special training program given to the disabled by using white cane. Various workshops and seminars are being conducted to sensitize the public, create awareness and advocacy.

(pp. 1-2)

The literature has divergent views regarding collaboration between support services for CWD in Bhutan. UNICEF (2013c) suggests that 'There are many examples of good, collaborative practice between education stakeholders in Bhutan which can be supportive of the country's inclusive education aspirations' (p. 55) and describes health workers and the MoE working together to assess CWD. Conversely, Tharchen and Savegpan (n.d.) describe 'poor collaborations among the stakeholders' (p. 80). Paradoxically, UNICEF (n.d.) agrees with Tharchen and Savegpan (n.d.), highlighting a lack of coordination across economic, health and education sectors as a 'main challenge' to providing 'quality inclusive education for CWD in Bhutan' (p. 2). Moreover, UNICEF (2014) notes that the paucity of data and systems around child protection present a further 'real challenge' (p. 2). In this regard, the Parliament of Bhutan (2011) states that the relevant support services are Dzongkhag child welfare committees and government employees and institutions. In schools, Pinnock (2013) noted that 'efforts to improve curricula and teaching practice should happen in full collaboration between "mainstream" teaching bodies and departments, and SEN/inclusion/disability experts', while Chhetri (2015) suggests there is value in professionals working together to develop children's individual education plans. UNICEF (2013c) is clear that 'Inclusion needs the broadest, deepest network of support possible' (p.xv).

Pinnock (2013) highlights the importance of stakeholder voices and practitioner empowerment for supporting CWD in Bhutan and UNICEF (n.d.) lists a wide range of stakeholders who are instrumental in promoting equal opportunities for CWD in Bhutan: the Ministries of Education, Health, Works and Human Settlement, the National Commission for Women and Children, civil society organizations including Draktsho, Ability Bhutan Society, Disabled Persons Association of Bhutan, Bhutan Foundation, religious leaders, parliamentarians, CWD and their families, the media and development partners.

UNICEF (2014) notes that national consultations conducted with children and adults concerning protection for CWD identified the need for more advocacy and increased awareness about challenges faced by CWD and their families, including discrimination and stigma. Thuji's study (2013) focused on 'The Role of Civil Service Organisations in Inclusive Education Development in Bhutan' to capture a range of stakeholders' voices and UNICEF (2013c) praises stakeholders in Bhutan for their 
'openness and willingness' to work collaboratively to support CWD (p. 55). It highlights the need to engage their voices regarding CWD, including development of an initial teacher education module focused on teaching children with SEN, teacher recruitment and retention and the use of English as a teaching medium for children with learning disabilities.

Tharchen and Savegpan (n.d.) indicated that children's progress to a higher grade is decided by their examination performance; since only a minority of principals and teachers adopt alternative assessment methods for CWD, Tharchen and Savegpan (n.d.) suggest it is likely that CWD will be excluded from education. Perhaps as a result of this, non-formal education in Bhutan tends to be oriented to adults who have missed out on education as children (Chhetri, 2015) it is differentiated to their needs and includes life skills, such as parenting (Mont et al., 2013; UNICEF, 2013c). The literature illustrates how resources are crucial and can be used to support CWD. Teachers are a key resource for supporting children to learn in schools (Barber and Mourshed, 2007). However, instead of 'active and engaged learning and participation' advocated by Chhetri (2015), the transmission mode of teaching prevails in the large classes inmost Bhutanese schools (VanBalkom \& Sherman, 2010). This is likely to hinder some students accessing the curriculum, particularly CWD.

However, RGoBMoE has proposed collaboration with the RGoB Ministry of Labour and Human Resources to secure an adequate supply of trained teachers to support inclusion (UNICEF, 2013c); as suggested elsewhere, an increase in salary has been introduced to attract candidates to a teaching career that is currently an unpopular option in Bhutan (VanBalkom \& Sherman, 2010). If, as Chhetri (2015) recommends the MoE Special Education Unit gives all teachers and trainee teachers at least basic training in inclusive education and SEN, Pinnock (2013) suggests that more knowledgeable teachers may be able to train others. She observed 'some strong (inclusive) practice in SEN units and schools, which could be shared and developed in mainstream schools - if mainstream teachers are given time to think about children and be flexible'. Chhetri (2015) also advocates recruitment of teaching assistants and suggests that training parent helpers to assist as support-workers in schools might be a viable option in a situation where training facilities are relatively weak.

Finally, the literature recognizes that national regulation and leadership are key elements in defining practices. National regulation in Bhutan includes examinations, as discussed above; however, UNICEF (2013c) warns against this practice, arguing that it 'can work against inclusion', as outcomes focused models tend to lead to school rankings (p. 55). UNICEF (2013c) has identifies the need to 'sensitize' school principals to inclusive education.

\section{Concluding observations}

Bhutanese policy seems committed to a social model of disability and respecting the rights of CWD through inclusive education. However, in practice, CWD often remain excluded from education and from wider community participation. In respect of attitudes to CWD in Bhutan, the literature indicates a country is in transition. Where CWD have been hidden from society in the past, more are now going to school and are more visible socially. Whilst segregation of CWD remains common, integration is currently rare and inclusion even more so; yet there appears to be strong policy commitment to inclusion and attempts have been made in recent years to translate policy into practice. Bhutan has made discernible progress in its practices oriented to supporting CWD; the literature indicates that there are particular challenges to be met in further developing inclusive orientations for CWD and that these are apparent in respect of knowledge acquisition, attitudeformation and ground-level practice. 
The purposive scoping attempted here suggests that, with regard to KAP in respect of CWD, the contemporary landscape is distinguished by several key characteristics. Firstly, there are notable parallels between Bhutan and the international literature in respect of KAP themes, but whilst the international literature is abundant, coverage in Bhutan is nascent. Secondly, in Bhutan there is a tendency to rely upon reports and other documentation derived from international agencies, charities or NGOs. This is less common in the case of literature concerning other international settings, where scholarly research and commentaries are more widely available. Finally, the literature indicates a broad correlation between the types of challenges facing educational systems at a global level and those in Bhutan. In the latter, however, particular environmental, cultural or physical challenges are apparent. Furthermore, because there has been a much shorter history of attempting to address the needs of CWD in Bhutan, there can be a tendency to rely on adapting models of inclusive practice drawn from those international settings with a longer-term tradition of development, even though an 'inclusive approach' to CWD at a worldwide level is still relatively new, having emerged in the late twentieth century as the preferred approach to securing equal and sustainable involvement of CWD.

\section{Disclosure statement}

No potential conflict of interest was reported by the authors.

\section{Notes on contributors}

Philip Garner was recently Professor of Education at the University of Northampton (UK).

Jane Murray is an Associate Professor and Senior Lecturer in Education based at the Centre for Education and Research at the University of Northampton, UK. She specialises in research and publications concerning education, early childhood education and social inclusion.

David Preece is an Associate Professor in the Centre for Education and Research. His main research interests focus upon autism and the experience of families living with disability.

Richard Rose is Professor of Inclusive Education at the University of Northampton. He has conducted research and consultancy in many parts of the world and was Principal Investigator on Project IRIS, a four-year longitudinal study of special educational needs provision in Ireland.

Yu Zhao is a Doctoral Student within the Faculty of Education and Humanities at the University of Northampton (UK), and has worked as a Research Assistant for several international projects.

\section{References}

Ainscow, M. (2005). Understanding the development of inclusive education systems. Electronic Journal of Research in Educational Psychology, 7(3), 5-20. Retrieved from http://www.investigacionpsicopedagogica.org/revista/articulos/7/english/Art_7_109.pdf

Alkire, S. (2015). Well-being, happiness, and public policy. Thimpu: The Centre for Bhutan Studies \& GNH Research.

Al Zyoudi, M, Al Sartwai, A., \& Dodin, H. (2011). Attitudes of pre-service teachers towards inclusive education in UAE and Jordan (a comparative study). International Journal of Disability, Community and Rehabilitation, 10(1), 0. www.ijdcr.ca/VOL10_01/articles/alzyoudi.shtml

ARACY. (2015). Inclusive education for children with disability. A review of best evidence in relation to theory and practice. 
The Australian Research Alliance for Children and Youth. Retrieved from

http://www.aracy.org.au/publicationsresources/command/download_file/id/246/filename/Inclusiv e_education_for_students_with_disability_-

_A_review_of_the_best_evidence_in_relation_to_theory_and_practice.pdf

Baker-Ericzén, M., Mueggenborg, M., \& Shea, M. (2009). Impact of training on child care providers' attitudes and perceived competence toward inclusion: What factors are associated with change. Topics in Early Childhood Special Education, 28(4), 196-208.

Barber, M. \& Mourshed, M. (2007). How the world's best-performing school systems come out on top. Retrieved from http://lst-iiep.iiep-unesco.org/cgibin/wwwi32.exe/[in=epidoc1.in]/?t2000=025763/(100)

Beaglehole, R., \& Bonita, R. (2015). Development with values: Lessons from Bhutan. The Lancet, 385, 848-849.

Birch, J., \& Johnstone, B. (1975). Mainstreaming a new public policy in education. Presented at the Annual Convention of the America Association of School Administrators, Dallas, Texas.

Biswas-Diener, R., Diener, E., \& Lyubchik, N. (2015). Wellbeing in Bhutan. International Journal of Wellbeing, 5(2), 1-13.

Booth, T., \& Ainscow, M. (2002). Index for inclusion: Developing learning and participation in schools. Bristol: Centre for Studies in Inclusive Education.

Brooks, J. S. (2011). Buddhism, economics, and environmental values: A multilevel analysis of sustainable development efforts in Bhutan. Society \& Natural Resources, 24(7), 637-655.

Business Bhutan. (2012, March 17). No country for the disabled. Business Bhutan [Online]. Retrieved from http://businessbhutan.bt/no-country-for-the-disabled/

Carroll, A., Forlin, C., \& Jobling, A. (2003). The impact of teacher training in special education on the attitudes of Australian preservice general educators towards people with disabilities. Teacher Education Quarterly, 30(3), 65-73.

Cassady, J. (2011). Teachers' attitudes toward the inclusion of students with autism and emotional behavioral disorder.Electronic Journal for Inclusive Education, 2, 7.

Chapman, C., Ainscow, M., Miles, S., \& West, M. (2011). Leadership that promotes the achievement of students with special educational needs and disabilities: Full report. Nottingham: National College of School Leadership.

Chhetri, K. K. (2015). Investigating teachers' concerns and experiences in teaching children with special educational needs in Bhutan (Unpublished MA Dissertation). Queensland University of Technology, Brisbane.

Childs, A., Tenzin, W., Johnson, D., \& Ramachandran, K. (2012). Science education in Bhutan: Issues and challenges. International Journal of Science Education, 34(3), 375-400.

Choden, P., \& Sarkar, D. (2013). Gender bias in schooling: The case for Bhutan. Journal of the Asia Pacific Economy, 18(4), 513-528.

Clarke, H. (2006). Preventing social exclusion of disabled children and their families: Literature review paper produced for the national evaluation of the children's fund. London: DfES. 
Cokl, U. (2010). The education system in Bhutan. Austro Bhutanese development and research cooperation. Vienna: Austrian.

Croot, E., Grant, G., Cooper, C., \& Mathers, N. (2008). Perceptions of the causes of childhood disability among Pakistani families living in the UK. Health and Social Care in the Community, 16(6), 606-613.

DCSF. (2007). The Bercow report, review of services for children and young people (0-19) with speech, language and communication needs. London: Author.

de Boer, A. A., \& Munde, V. S. (2015). Parental attitudes toward the inclusion of children with profound intellectual and multiple disabilities in general primary education in the Netherlands. The Journal of Special Education, 49(3), 179-187.

de Boer, A., Pijl, S.-J. , \& Minnaert, A. (2011). Regular primary school teachers' attitudes towards inclusive education: A review of the literature. International Journal of Inclusive Education, 15(3), 331-353.

Dorji, C. (2004). Achieving gross national happiness through community-based mental health services in Bhutan, gross national happiness and development. In Proceedings of the First National Conference on Operationalisation of Gross National Happiness, 2004, 599-627. Retrieved from www. bhutanstudies.org.bt/publicationFiles/ConferenceProceedings/GNHandDevelopment/34.GNH \&development.pdf

Dorji, C. (2012). Achieving gross national happiness through community-based mental health services in Bhutan. Gross national happiness and development, proceedings of the first national conference on operationalisation of gross national happiness (pp. 599-627). Retrieved from http://www. bhutanstudies.org.bt/publicationFiles/ConferenceProceedings/GNHandDevelopment/3 4.GNH\&development.pdf

EADSNE. (2011). Teacher education for inclusion across Europe - challenges and opportunities. Odense: Author.

EADSNE. (2012). The inclusive education in action project. Odense: Author.

Elkins, J., van Kraayenoord, C., \& Jobling, A. (2003). Parents' attitudes to inclusion of their children with special needs. Journal of Research in Special Educational Needs, 3(2), 122-129.

Finke, E., McNaughton, D., \& Drager, K. (2009). "All children Can and should have the opportunity to learn": general education teachers' perspectives on including children with autism spectrum disorder who require AAC. Augmentative and Alternative Communication, 25(2), 110-122.

Gerschel, L. (2003). Connected the disconnected: Exploring issues of gender, race and SNE within an inclusive context. London: David Fulton Publisher.

Gibson, C. (2008). Overcoming the stigma of the learning disability label: A story of survival and recovery. ACA Special Education News, Article LD-8-3.

Givel, M. S. (2015). Gross national happiness in Bhutan: Political institutions and implementation. Asian Affairs, 46(1), 102-117.

Goldberg, I., \& Lippman, L. (1974). Plato had a word for it. Exceptional Children, 40(5), 325-334. 
Gordon, J. A. (2013). Bhutan: Educational challenges in the land of the Thunder Dragon. Ethnography and Education, 8(3), 286-300.

Hassanein, E. (2015). Inclusion, disability and culture. Rotterdam: Sense Publishers.

Hobbs, M. (1973). The future of children categories and their consequences. San Francisco: Jossey Bass.

Kaliyaperumal, K. (2004). Guideline for conducting a knowledge, attitude, and practice (KAP) study. Community Ophthalmology, 4, 7-9.

Lemacks, J., Fowles, K., Mateus, A., \& Thomas, K. (2013). Insights from parents about caring for a child with birth defects. International Journal of Environmental Research and Public Health, 10(8), 3465-3482.

Leyser, Y., \& Kirk, R. (2004). Evaluating inclusion: An examination of parent views and factors influencing their perspectives. International Journal of Disability, Development and Education, 51(3), 271-285.

Lham, T. (2013). The attitude and perception of Bhutanese teachers towards inclusive education. Paper presented at the Regional Seminar on Inclusive Education with focus on CWD, Paro College of Education, 3-5 December 2013.

MacQueen, K., McLellan, E., Metzger, D., Kegeles, S., Strauss, R., Scotti, R.,...Trotter, R. (2001). What is community? An evidence-based definition for participatory public health. American Journal of Public Health, 91(12), 1929-1938.

Maxwell, T. W., Rinchen, P., \& Cooksey, R. (2010). Evolutionary trajectories in school assessment systems: The case of Bhutan. Asia Pacific Journal of Education, 30(3), 273-288.

Meijer, C. (2001). Inclusive education and effective classroom practices. Brussels: European Agency for Development in Special Needs Education.

Metz, T. (2014). Gross national happiness: A philosophical appraisal. Ethics and Social Welfare, 8(3), 218-232.

Mont, D., Cappa, C., Chetri, N. B., Dorji, C., Hingst, G., Khan, N., \& Penjor, K. (2013). Poverty, maternal education and child disability: Evidence from Bhutan. Behinderung und Internationale Entwicklung, 3, 13-20.

National Statistics Bureau, Bhutan and Asian Development Bank. (2012). Bhutan living standards survey 2012 report. Thimpu: Author.

National Statistics Bureau, Ministry of Education, Ministry of Health, UNICEF. (2012). Two stage child disability study among children aged 2-9 years. Bhutan 2010-2011. Thimpu: National Statistics Bureau.

National Statistics Bureau/Ministry of Education/UNICEF. (2014). Bhutan education blueprint, 201424. Thimphu: NSB/MoE/UNICEF.

NDA. (2006). Literature review on attitudes towards disability. Dublin: Author.

OECD. (2005). Students with disabilities, learning difficulties and disadvantages: Statistics and indicators. Paris: OECD/CERI. 
Osberg, D., \& Biesta, G. (2010). The end/s of education: Complexity and the conundrum of the inclusive educational curriculum. International Journal of Inclusive Education, 14(6), 593-607.

Parker, C., \& Ford, T. (2013). Editorial perspective: School exclusion is a mental health issue. Journal of Child Psychology and Psychiatry, 54(12), 1366-1368.

Parker, W., Gage, H., \& Sterr, A. (2011). Services for families with disabled children, a scoping study, Final Report. Guildford: The University of Surrey.

Parliament of the Kingdom of Bhutan. (2011). The child care and protection act. Thimpu: Author. [Online]. Retrieved from https://www. mindbank.info/item/5709

Pellegrini, L., \& Tasciotti, L. (2014). Bhutan: Between happiness and horror. Capitalism Nature Socialism, 25(3), 103-109.

Pinnock, H. (2013, December 3-5). Education for CWD: Needs assessment in Maldives and Bhutan. Paper presented at the Regional Seminar on Inclusive Education with focus on CWD. Paro College of Education.

Purdue, K., Gordon-Burns, D., Gunn, A., Madden, B., \& Surtees, N. (2009). Supporting inclusion in early childhood settings: Some possibilities and problems for teacher education. International Journal of Inclusive Education, 13(8), 805-815.

Rafferty, Y., \& Griffin, K. (2005). Benefits and risks of reverse inclusion for preschoolers with and without disabilities: Perspectives of parents and providers. Journal of Early Intervention, 27(3), 173192.

Reiser, R. (2013). Teacher education for CWD: Literature review. Manchester: EENET.

Royal Government of Bhutan. (2012). National export strategy (Vol. 1). Thimpu: Author.

Royal Government of Bhutan Ministry of Education. (2009). Annual education statistics, 2009.

Thimpu: Policy and Planning Division, Ministry of Education.

Royal Government of Bhutan Ministry of Education. (2011). Annual education statistics, 2011. Thimpu: Policy and Planning Division, Ministry of Education.

Royal Government of Bhutan Ministry of Education. (2012a). Annual education statistics, 2012. Thimpu: Policy and Planning Division, Ministry of Education.

Royal Government of Bhutan Ministry of Education. (2012b). National policy on special educational needs. [Online]. Retrieved from http://www.education.gov.bt/documents/10180/12859/Final-DraftSEN-Policy-2012. pdf/2bd136d1-71af-41d7-8819-a2d177e75049?version=1.0

Royal Government of Bhutan Ministry of Education. (2014). Annual education statistics, 2014. Thimpu: Policy and Planning Division, Ministry of Education.

Samaha, A. (2007). What good is the social model of disability? Public law and legal theory working papers. Chicago: University of Chicago Law School.

Schuelka, M. J. (2013). An inclusive education in Bhutan. Current Issues in Comparative Education, 15(1), 145-156.

Schuelka, M. J. (2015). The evolving construction and conceptualisation of 'disability' in Bhutan. Disability \& Society, 30(6), 820-833. 
SCOPE. (2014). Public awareness towards disability. London: Author.

Shakespeare, T., \& Kleine, I. (2015). Educating health professionals about disability: A review of interventions. Health and Social Care Education, 2(2), 20-37.

Singal, N., \& Muthukrishna, N. (2014). Education, childhood and disability in countries of the south: Re-positioning the debates: An introduction. Childhood, 21(3), 293-307.

Siperstein, G., Norins, J., Corbin, S., \& Shriver, T. (2003). Multinational study of attitudes towards individuals with intellectual disabilities. Washington: Special Olympics Inc.

Skotko, B., \& Canal, R. (2005). Postnatal support for mothers of children with down syndrome. Mental Retardation, 43, 196-212.

Solomon, P., \& Dorji, S. (2009). Attitudes of health professionals toward persons with disabilities in Bhutan. Asia Pacific Disability Rehabilitation Journal, 20(2), 32-42.

Tharchen, C. T. C., \& Savegpan, P. (n.d.). A study on management of inclusive education in Bhutanese school education system: Policy, practices and perceptions (Unpublished master's dissertation).

Thomas, N. (2011). 'Children's rights' policy into practice', Centre for Children and Young People: Background Briefing Series, No. 4. Lismore, NSW, Australia: Centre for Children and Young People, Southern Cross University.

Thuji, Z. (2013). Role of civil society organizations in inclusive education development in Bhutan. Thimpu: Ability Bhutan. Paper presented at the Regional Seminar on Inclusive Education with focus on CWD.Paro College of Education, 3-5 December 2013.

UNESCO. (1994). The Salamanca statement and framework for action on special needs education. Paris: Author.

UNESCO. (2000). The Dakar framework for action. Paris: Author.

UNESCO. (2005). Guideline for inclusion: Ensuring access to education for all. Paris: Author.

UNICEF. (2007). An overview of child well-being in rich countries. Report Card 7. Innocenti Research Centre. Florence: Author.

UNICEF. (2013a). Children and young people with disabilities. Fact sheet. New York, NY: Author.

UNICEF. (2013b). UNICEF annual report 2013 - Bhutan. New York, NY: Author.

UNICEF. (2013c). Meeting the educational needs of CWD in south Asia: A gap analysis covering Bhutan and the Maldives. Kathmandu: Author.

UNICEF. (2013d). UNICEF annual report 2013 - Bhutan. New York: Author.

UNICEF. (2013e). Bhutan statistics. [Online]. Retrieved from http://www.unicef.org/infobycountry/bhutan_statistics.html

UNICEF. (2014). Bhutan annual report 2014. [Online]. Retrieved from http://www.unicef.org/about/annualreport/files/Bhutan_Annual_Report_2014.pdf

UNICEF. (n.d.). Promoting equal opportunities for CWD in Bhutan. Thimpu: Author. United Nations. (1989). UN convention on the rights of the child. New York, NY: Author. 
United Nations. (1989). UN convention on the rights of the child. New York, NY: Author.

United Nations. (2006). Convention on the rights of persons with disabilities. [Online]. Retrieved from http://www.un.org/disabilities/convention/conventionfull.shtml

United Nations. Department of Economic, \& United Nations. Department of Public Information.

(2009). The millennium development goals report 2009. New York, NY: United Nations Publications.

Ura, K., Alkire, S., Zangmo, T., \& Wangdi, K. (2012). An extensive analysis of GNH index. Thimpu: The Centre for Bhutan Studies.

VanBalkom, W. D., \& Sherman, A. (2010). Teacher education in Bhutan: Highlights and challenges for reform. Asia Pacific Journal of Education, 30(1), 43-55.

Wangchuk, K. C., Choden, R., Choden, K., Zangpo, S., \& Yangden (n.d.). The status of early childhood care and development in Bhutan: An internal report for ECCD situational study. [Online]. Retrieved from http://www.rec.org.bt/wp-

content/uploads/nivoslider4wp_files/The\%20Status\%20of\%20Early\%20Childhood\%20Care\%20and\% 20Development\%20in\%20Bhutan.pdf

Winter, E., \& O'Raw, P. (2010). Literature review of the principles and practices relating to inclusive education for children withspecial educational needs. Trim: NCSE.

World Bank. (2009). People with disabilities in India: From commitments to outcomes. Washington: Author.

World Health Organization. (2011). World report on disability. Geneva: Author. Retrieved from http://www.who.int/disabilities/world_report/2011/en/index.html

World Health Organization. (2012). Situation analysis of community based rehabilitation in the South East Asia region. New Delhi: Author.

Young, M. (2009). Basic capabilities, basic learning outcomes and thresholds of learning. Journal of Human Development and Capabilities, 10(2), 259-277.

Youth Development Fund Secretariat. (2014). A strategic plan for the child protection and care services (CPCS) for youth development fund (YDF): 2014. Thimpu: Author.

Zangmo, D. (n.d.). Empowering girls and women with disabilities in rural areas. 0: 0 . Retrieved from www.un.org/disabilities/documents/csw/csw56_zam.doc

Zimmer, Z. (2008). Poverty, wealth inequality and health among older adults in rural Cambodia.

Social Science \& Medicine, 66(1), 57-71. 


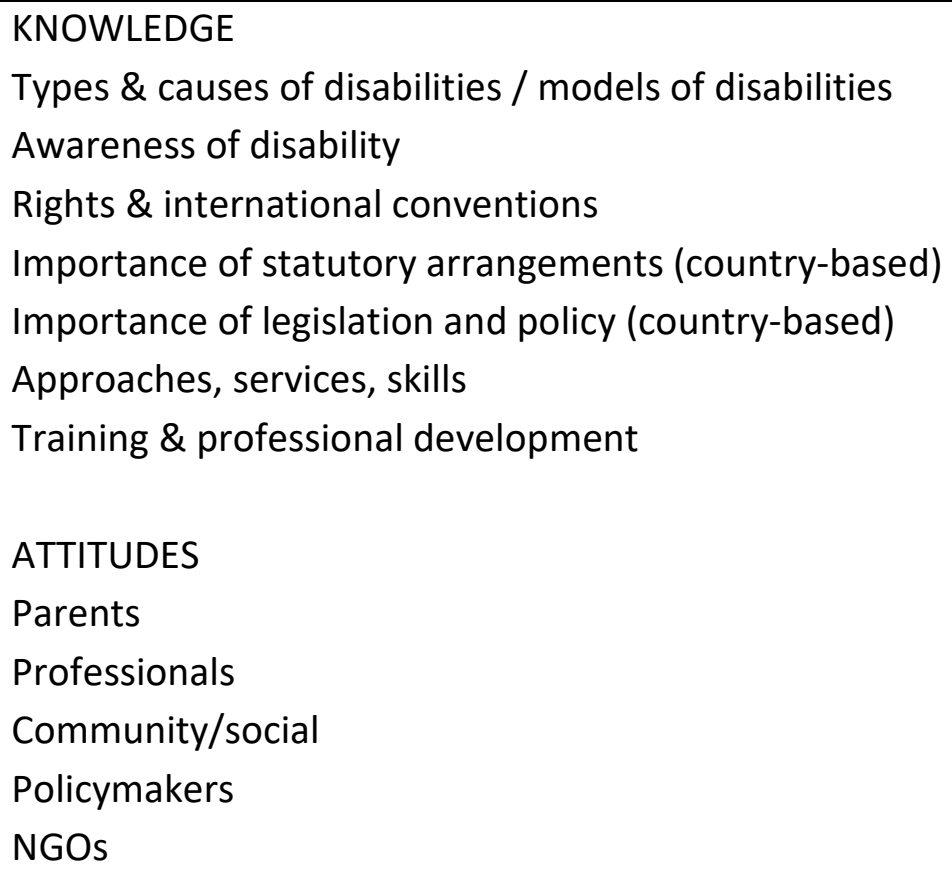

Figure 1: Map of primary and secondary search terms 